Nov 2017 a Abr $2018-$ v.8 - n.1

\title{
Indicação de madeiras da caatinga para uso na produção de brinquedo
}

O brinquedo tem característica de material pedagógico relevante para a aprendizagem de uma criança, sendo que brinquedos de madeira são mais engraçados e didáticos. Assim, ligando a essa arte encontra-se o avanço das tecnologias e pesquisas para caracterizar e analisar qual melhor espécie de madeira se adequada para construção de brinquedos. Nesse contexto, o objetivo desse estudo foi indicar as madeiras da Caatinga apropriadas para a utilização na produção de brinquedos. A pesquisa foi realizada no período compreendido entre 1986 a 2017, através da revisão de literatura. Foram selecionadas 19 espécies baseando-se nos maiores índices de valor de importância (IVI), expresso em estudos realizados no bioma caatinga, e em seguida, estabeleceu critérios classificatório e eliminatório para determinar as madeiras mais adequadas para utilizar como matéria-prima para produção de brinquedos. No critério de densidade, foi observado que a densidade varia 0,43 a $1,00 \mathrm{~g} / \mathrm{cm}^{3}$. Pode-se notar, ainda, que $55 \%$ das espécies estão classificadas dentro das categorias pesada, $27 \%$ moderadamente pesada e $18 \%$ leve. Deste modo, concluímos que das 19 espécies avaliadas, apenas cinco espécies atendem aos requisitos para serem utilizadas na fabricação de brinquedos. Sendo elas: Imburana, Empiratanha, Pereiro, Angico-vermelho e Jurema-branca. Além disso, as espécies Pereiro e Angico-vermelho apesar de não apresentar fácil trabalhabilidade também pode ser uma boa indicação de uso na falta das espécies de fácil trabalhabilidade.

Palavras-chave: Brinquedos; Imburana; Semiárido.

\section{Indication of caatinga woods for use in toy production}

The toy has the characteristic of pedagogical material relevant to the learning of a child, and wooden toys are funnier and didactic. Thus, linking to this art is the advance of technologies and research to characterize and analyze which best kind of wood is suitable for building toys. In this context, the objective of this study was to indicate Caatinga wood suitable for use in the production of toys. The research was carried out in the period from 1986 to 2017 , through the literature review. A total of 19 species were selected based on the highest values of importance (IVI), expressed in studies carried out in the caatinga biome, and then established classification and eliminatory criteria to determine the most suitable woods to use as raw material for the production of toys. In the density criterion it was observed that the density varies from 0.43 to $1.00 \mathrm{~g} / \mathrm{cm}^{3}$. It can also be noted that $55 \%$ of the species are classified as heavy, $27 \%$ moderately heavy and $18 \%$ light. Thus, we conclude that of the 19 species evaluated, only five species meet the requirements to be used in the manufacture of toys. They are: Imburana, Empiratanha, Pereiro, Angico-rouge and Jurema-branca. In addition, the Pereiro and Angico-Vermelho species, although not easy to work, can also be a good indication of use in the absence of easily workable species.

Keywords: Toys; Imburana; Semi-arid.

\section{Topic: Ciências Florestais}

Reviewed anonymously in the process of blind peer.
Received: $14 / 01 / 2019$

Approved: 24/04/2019

Emanuel Lucas Bezerra Rocha (iD)

Universidade Federal Rural do Semiárido, Brasil

http://orcid.org/0000-0002-1265-0698

rochaflorestal@gmail.com

Referencing this:

ROCHA, E. L. B.. Indicação de madeiras da caatinga para uso na produção de brinquedo. Natural Resources, v.8, n.1, p.9-16, 2018. DOI: $\underline{\text { http://doi.org/10.6008/CBPC2237-9290.2018.001.0002 }}$

DOI: 10.6008/CBPC2237-9290.2018.001.0002 


\section{INTRODUÇÃO}

O brincar faz parte do universo de toda criança, assim elas aprendem de maneira mais significativa, se socializam com facilidade, desenvolve-se a criatividade, apreendem o espírito de grupo (ISCHKANIAN, et al., 2017), desenvolve o raciocino lógico rápido nas tomadas de decisões, além de ajudar no desenvolvimento motor da criança e a formação da identidade infantil (ISCHKANIAN et al., 2017).

Nesse sentido, o brinquedo tem característica de material pedagógico relevante para a aprendizagem de conceitos, procedimentos e atitudes, possibilitando, ambientes desafiadores (PIMENTA, 2017), capazes de 'estimular o intelecto' e, consequentemente, conquistar estágios mais elevados de raciocínio. Além disso, o brinquedo estimula a construção do pensamento, do conhecimento e da autonomia.

Outros fatores podem ser observados no campo dos brinquedos, como por exemplo o tamanho, formato e cor (FREITAS, 2007). Brinquedos pequenos exigem a presença de adultos para sua manipulação, tornando esse ato uma emancipação social (CHAIGAR et al., 2015). Já com relação a brinquedos maiores, além da diversidade de objetos criados que houve com o passar dos anos, também teve uma crescente subtração ao controle da família, tornando assim, uma atividade livre, desenvolvendo nas crianças/adolescentes um senso de crítico (CORDEIRO, 2015). O formato também parece ter uma importância muito maior do que se pode imaginar. Pois esse formato pode limitar a possibilidade de a criança brincar (ZATZ, 2007), direcionando o modo como ela se relaciona com o brinquedo.

A arte de construir brinquedos usando materiais alternativos como madeira, que podem ser reutilizados como recursos para a produção de instrumentos para o desenvolvimento de atividades lúdicas na educação ou em tratamentos terapêuticos (OLIVEIRA, 2015), podem produzir resultados na formação de indivíduos únicos, autênticos e criativos, seres preparados para as incertezas de um futuro que logo se aproxima na construção das noções de responsabilidades com o meio ambiente (CORDEIRO, 2015).

Assim, ligando a essa arte encontra-se, tem o avanço das tecnologias e pesquisas para caracterizar e analisar qual melhor espécie de madeira se adequada para construção de brinquedos. Os principais parâmetros para estudos relacionados à tecnologia da madeira, que auxiliam na análise dos resultados e na destinação correta do produto de acordo com o uso, são a composição química (SJÖSTRÖM, 1993), a estrutura anatômica (BURGER et al., 1991) e a densidade (MEDEIROS NETO et al., 2012).

O estudo da qualidade da madeira de espécies nativas é fundamental para avaliar um conjunto de características que determinam o seu uso, visando a exploração em regime de rendimento sustentável. Segundo Ramos et al. (2013) aponta para utilização da madeira como uma oportunidade para o mercado de brinquedos, é visto como um diferencial e também estimular o uso de materiais de origem natural.

A madeira se apresenta como um material abundante no Brasil, de fonte renovável. O designer observando isso pode configurar um brinquedo para a função de brincar, e também pode conscientizar pais, escolas e crianças (futuros adultos) da importância de utilizar a madeira de forma racional e desprezar outras matérias primas não renováveis. Tendo em vista, orientar a escolha da espécie de madeira adequada aos requisitos de projeto de um brinquedo, este trabalho é útil à designers, pais e profissionais que trabalham 
com crianças. Assim, o objetivo desse estudo foi indicar as madeiras da Caatinga apropriadas para a utilização na produção de brinquedos.

\section{METODOLOGIA}

A pesquisa foi realizada no período compreendido entre 1986 A 2017, através da revisão de literatura, onde inicialmente, as espécies foram selecionadas baseando-se nos maiores índices de valor de importância (IVI), expresso em estudos realizados no bioma caatinga (SANTOS et al., 2017; SANTANA et al., 2016; MARANGON et al., 2013) Quadro 1.

Quadro 1: Espécies Nativas da Caatinga.

\begin{tabular}{|c|c|}
\hline Espécie & Nome Vulgar \\
\hline Poincianella pyramidalis & Catigueira \\
\hline Handroanthus impertiginosus & Pau Dárco \\
\hline Myracrodruon urundeuva & Jureeira \\
\hline Mimosa tenuiflora (Willd.) Poiret & Pereiro \\
\hline Aspidosperma pyrifolium Mart & Marmeleiro \\
\hline Croton sonderianus Müll.Arg. & Mororó \\
\hline Bauhinia cheilantha (Bong.) Steud. & Imburana \\
\hline Commiphora leptophloeos (Mart.) J.B.Gillett & Pinhão-Bravo \\
\hline Jatropha curcas & Burra-Leiteira \\
\hline Sapium sceleratum & Cumaru \\
\hline Amburana cearensis & Angico-vermelho \\
\hline Anadenanthera colubrina var. cebil & Mofumbo \\
\hline Combretum leprosum Mart. & Sabiá \\
\hline Mimosa caesalfiniaefolia Benth & Jurema-branca \\
\hline Piptadenia stipulacea (Benth.) Ducke & Maniçoba \\
\hline Pseudobobax marginatum (A. St.-H.L) A. Robyns & Empiratanha \\
\hline Cnidoscolus quercifoliusPohl & Faveleira \\
\hline
\end{tabular}

Após a determinação das espécies que seriam avaliadas, criou-se critérios baseados no que Melo et al. (2016) utilizou para classificar as melhores espécies para a produção de pequenos objetos de madeira. Esse estudo foi dividido em duas fases, eliminatória e classificatória. Na fase eliminatória foi avaliado os seguintes requisitos: configuração que forneçam segurança (toxidade); apresentar boas características sensitivas as crianças e ser leve, facilitando a manipulação pelas crianças sem riscos (Densidade). Já na fase classificatória foi avaliado: apresentar boa característica quanto a sua trabalhabilidade.

Na fase eliminatória analisamos primeiramente a toxicidade através de pesquisa bibliográfica sobre as famílias ou espécies, que pode oferecer perigo a segurança física de crianças, sendo classificada como apta e não apta. Avaliada a toxidade, as espécies aptas foram ponderadas de acordo com as caraterísticas sensitivas das espécies, sendo considerada espécies aptas aquelas que apresentassem textura fina á media.

Por fim, seguiu-se analisando a densidade, onde as espécies restantes passaram por uma classificação com critérios de densidade estabelecidos por Mainieri et al. (1989), podendo observar, na Tabela 1, onde as espécies foram classificadas em 'Pesada' eram consideradas 'Não apta'. Ainda nessa fase analisou as espécies restante quanto a sua durabilidade, sendo considerada 'Aptas' as espécies que apresentassem durabilidade de média a alta. 
Tabela 1: Classificação por densidade.

\begin{tabular}{ll}
\hline Densidade & \\
\hline Valor & Classificação \\
\hline$D \leq 0,40$ & Muito leve \\
\hline $0,40<D \leq 0,55$ & Leve \\
\hline $0,55<D \leq 0,75$ & Moderadamente Pesada \\
\hline $0,75<D \leq 0,95$ & Pesada \\
\hline
\end{tabular}

Fonte: Adaptado de Mainieri et al. (1989).

Após a análise das espécies na fase eliminatória, as espécies restantes consideradas 'Aptas' seguiram para fase classificatória, onde foi estabelecido uma ordem de espécies mais indicadas de acordo com sua trabalhabilidade.

\section{RESULTADOS E DISCUSSÃO}

\section{Fase eliminatória: Segurança e Características Sensitivas}

O primeiro requisito foi a segurança, como a madeira é de origem natural e várias espécies podem apresentar toxicidade verificou-se que, segundo Oliveira (1989), as plantas tóxicas são àquelas que introduzidas no organismo do homem ou animal seja capaz de ocasionar danos que se reflete na saúde e vitalidade desses seres. Todo vegetal é potencialmente tóxico, sendo que uma planta tóxica ocasiona um desequilíbrio que se traduz no paciente como sintomas de intoxicação.

De acordo com Cruz (1995), as espécies da família Euphorbiaceae possuem um princípio tóxico ainda não bem identificado, parecendo ser uma toxoalbumina ou uma saponina ou uma fração solúvel em água, determinando, quando ingerida, intensa irritação gastrintestinal, e complicações hidreletrolíticas, com cólicas violentas, vômitos e diarreia intensa, que caracteristicamente se iniciam logo após a ingestão.

Além disso, nas plantas da família Anacardiaceae tem sido encontrado um potencial tóxico-irritante, no qual é atribuído, principalmente, à presença de derivados fenólicos encontrados em suas espécies (PELL, 2004). Um exemplo de espécie dessa família é a aroeira que é conhecida pelo alto poder sensibilizante e irritante capaz de ocasionar alergias, reações urticantes, eczemas e dermatites, frequentemente relatados por indivíduos que tem contado com a espécie (DIÓGENES et al., 1999; MONTEIRO et al., 2006; FORTES et al., 2006; MOTA, 2006). Com base nessas afirmações, não recomendamos o uso de espécies oriundas da família Euphorbiaceae, anacardiaceae para fabricação de brinquedos, estão: Pinhão-Bravo (Jatropha curcas), Burra-Leiteira (Sapium sceleratum), Marmeleiro (Croton sonderianus Müll.Arg.), Maniçoba. Faveleira e Aroeira (Myracrodruon urundeuva), vide Tabela 2.

Tabela 2: Espécies utilizadas na pesquisa.

\begin{tabular}{|l|l|l|}
\hline Espécie & Nome Vulgar & Classificação \\
\hline Poincianella pyramidalis & Catigueira & Apta \\
\hline Handroanthus impertiginosus & Pau Dárco & Apta \\
\hline Myracrodruon urundeuva & Aroeira & Não apta \\
\hline Mimosa tenuiflora (Willd.) Poiret & Jurema-preta & Apta \\
\hline Aspidosperma pyrifolium Mart & Pereiro & Apta \\
\hline Croton sonderianus Müll.Arg. & Marmeleiro & Não apta \\
\hline Bauhinia cheilantha (Bong.) Steud. & Mororó & Apta \\
\hline Commiphora leptophloeos (Mart.) J.B.Gillett & Imburana & Apta \\
\hline Jatropha curcas & Pinhão-Bravo & Não apta \\
\hline
\end{tabular}




\begin{tabular}{|l|l|l|}
\hline Sapium sceleratum & Burra-Leiteira \\
\hline Amburana cearensis & Cumaru \\
\hline Anadenanthera colubrina var. cebil & Angico-vermelho \\
\hline Combretum leprosum Mart. & Mofumbo \\
\hline Mimosa caesalfiniaefolia Benth & Sabiá \\
\hline Piptadenia stipulacea (Benth.) Ducke & Jurema-branca \\
\hline Manihot cartaginenses subsp. glaziovii (Muell. Arg.) Allem & Maniçoba \\
\hline Pseudobobax marginatum (A. St.-H.L) A. Robyns & Embiratanha \\
\hline Cnidoscolus quercifoliusPohl & Faveleira \\
\hline
\end{tabular}

Além da toxidade, as características sensitivas também podem nos ajudar na definição de qual espécie utilizar para obter um produto adequado aos requisitos. Quanto à textura, uma espécie é classificada como grossa, cinco como médias e seis são finas.

Tabela 3: Características sensitivas (textura).

\begin{tabular}{|l|l|l|}
\hline Nome Vulgar & Textura & Classificação \\
\hline Catigueira & Média & Apta \\
\hline Pau Dárco & Fina & Apta \\
\hline Jurema-preta & Média & Apta \\
\hline Pereiro & Fina & Apta \\
\hline Mororó & Fina & Apta \\
\hline Imburana & Média & Apta \\
\hline Cumaru & Fina & Apta \\
\hline Angico-vermelho & Média & Apta \\
\hline Mofumbo & Grossa & Não apta \\
\hline Sabiá & Fina & Apta \\
\hline Jurema-branca & Média & Apta \\
\hline Embiratanha & Fina & Apta \\
\hline
\end{tabular}

Fonte: Adaptado de Lorenzi (2009), Rizzini (2008) e Lima (2012).

\section{Densidade e Durabilidade}

A densidade é uma das principais características dos materiais, e em relação a essa, Moreschi (2005) afirma, que a partir da densidade (massa específica) dependem a maior parte de suas propriedades físicas e tecnológicas, servindo na prática como uma referência para a classificação da madeira. Com base nos critérios de classificação da Tabela 1 observemos na Tabela 4, com as densidades das espécies indicadas para fabricação de brinquedos (excluindo as da família Euphorbiaceae e demais espécies com princípio toxico, além de espécies com textura grossa).

$\mathrm{Na}$ tabela 4, observamos que a densidade varia 0,43 a $1,00 \mathrm{~g} / \mathrm{cm}^{3}$. Notamos, ainda, que $55 \%$ das espécies estão classificadas dentro das categorias pesada, $27 \%$ na moderadamente pesada e $18 \%$ na leve. De acordo com Moreschi (2005), em regra geral, madeiras pesadas são mais resistentes, elásticas e duras, enquanto que as leves, são de mais fácil trabalhabilidade, mostrando que a maioria das espécies utilizadas estão em um nicho de espécies resistentes e duras.

Tabela 4: Densidades de espécies da caatinga.

\begin{tabular}{|l|l|l|l|}
\hline Nome Vulgar & $\begin{array}{l}\text { Densidade } \\
\left(\mathbf{g}-\mathbf{c m}^{\mathbf{3}} \mathbf{~}\right.\end{array}$ & Classificação (Densidade) & $\begin{array}{l}\text { Classificação } \\
\text { (critério) }\end{array}$ \\
\hline Catigueira & 0,80 & Pesada & Não apta \\
\hline Pau Dárco & 0,99 & Pesada & Não apta \\
\hline Jurema-preta & 0,93 & Pesada & Não apta \\
\hline Pereiro & 0,62 & Moderadamente pesada & Apta \\
\hline Mororó & 0,97 & Pesada & Não apta \\
\hline Imburana & 0,43 & Leve & Apta \\
\hline
\end{tabular}




\begin{tabular}{|l|l|l|l|}
\hline Cumaru & 1,00 & Pesada & Não apta \\
\hline Angico-vermelho & 0,73 & Moderadamente pesada & Apta \\
\hline Sabiá & 0,80 & Pesada & Não apta \\
\hline Jurema-branca & 0,63 & Moderadamente pesada & Apta \\
\hline Embiratanha & 0,54 & Leve & Apta \\
\hline
\end{tabular}

Fonte: Adaptado de Paes et al. (2013), Almeida (2010), Santos et al. (2013) e Neto et al. (2014).

Considerando que os requisito estabelecidos para fabricação de brinquedos de madeira, com relação a classificação da densidade, podemos afirmar que as madeira leves e as moderadamente pesadas são as mais indicadas para este uso. Assim, as espécies mais indicadas para produção de brinquedos de acordo com esse estudo são, pereiro, Imburana, Angico-vermelho, jurema branca e Embiratanha. Outra propriedade que pode interferir na fabricação do brinquedo, é a durabilidade da madeira, pois torna o brinquedo economicamente viável, pois a utilização de preservantes iria encarecer o produto final, além de reduzir a utilização para crianças (Tabela 5).

Tabela 5: Características mecânica (durabilidade).

\begin{tabular}{|l|l|l|}
\hline Nome Vulgar & Durabilidade & Classificação \\
\hline Pereiro & Alta & Apta \\
\hline Imburana & Média & Apta \\
\hline Angico-vermelho & Alta & Apta \\
\hline Jurema-branca & Alta & Apta \\
\hline Embiratanha & Média & Apta \\
\hline
\end{tabular}

Fonte: Adaptado de Lorenzi (2009) e Rizzini (2008).

\section{Fase classificatória: Trabalhabilidade}

O resultado do presente estudo é condizente a outros trabalhos que avaliaram o conhecimento popular, tendo a imburana como a espécie mais utilizada no artesanato, principalmente na confecção de esculturas chamadas de 'carrancas' (CARVALHO, 2009), Silva et al. (2017) também reforça essa afirmação sobre a importância dessa espécie para as comunidades locais do semiárido para esculturas domesticas e rurais (Tabela 6).

Com relação a segunda espécie e acordo com a ordem desse estudo, Lima (2012) estudando as espécies da caatinga afirma que a Embiratanha é uma madeira fácil de ser trabalhada, onde pode ser utilizada na confecção de caixotes, brinquedos. Cepas de tamancos e na produção de cordas rusticas (embira).

As espécies Pereiro e Angico-vermelho apesar de não apresentar fácil trabalhabilidade também pode ser uma boa indicação de uso na falta das espécies de fácil trabalhabilidade. Estudos demostram que essas espécies são indicadas para atividades como marcenaria e carpintaria, principalmente na confecção de utensílios caseiros, instrumentos e cabos de ferramenta (LIMA, 2012; BRAGA, 1960).

Tabela 6: Classificação de espécies da caatinga de acordo com trabalhabilidade.

\begin{tabular}{|l|l|l|}
\hline Ordem & Nome Vulgar & Trabalhabilidade \\
\hline $\mathbf{1}$ & Imburana & Fácil \\
\hline $\mathbf{2}$ & Embiratanha & Fácil \\
\hline $\mathbf{3}$ & Pereiro & Intermediaria \\
\hline $\mathbf{4}$ & Angico-vermelho & Intermediaria \\
\hline $\mathbf{5}$ & Jurema-branca & Difícil \\
\hline
\end{tabular}

Fonte: Adaptado de Lorenzi (2009) e Rizzi (2008). 


\section{CONCLUSÕES}

Verificamos que para atender aos requisitos estabelecidos para brinquedos, as espécies de madeira mais adequadas são as com a densidade classificadas de leve a moderadamente pesada, pois oferecem leveza ao produto final e fácil trabalhabilidade na produção. É importante atentar para essa propriedade, pois orienta a combinação de diferentes espécies em uso no mesmo produto. Em relação as características sensitivas percebemos semelhanças, onde seis espécies possuem textura fina, caracterizando assim, ótimas espécies para essa finalidade, pois dispensa um maior gasto com tratamento superficial, além de não gerar risco à criança.

Deste modo, concluímos que das 19 espécies avaliadas, apenas cinco espécies atendem aos requisitos para serem utilizadas na fabricação de brinquedos. Sendo elas: Imburana, Embiratanha, Pereiro, Angico-vermelho e Jurema-branca. Por fim, ressalto que este trabalho é um estudo teórico, inicial, sendo necessário o aprofundamento dessas espécies em laboratórios.

\section{REFERÊNCIAS}

ALMEIDA, A. M. C.. Avaliação anatômica, físico-química e energética da madeira das espécies Piptadenia stipulacea (Benth.) Ducke e Amburana cearensis (Allemao) A. C. Smith de ocorrência no semiárido nordestino brasileiro. Campina Grande, 2010.

BRAGA, R.. Plantas do Nordeste, especialmente do Ceará. 2 ed. Fortaleza: DO, 1960.

BURGER, L. M.; RICHTER, H. G.. Anatomia da madeira. São Paulo: Nobel, 1991.

CARVALHO, P. E. R.. Imburana-de-Espinho Commiphora leptophloeos. Comunicado técnico. Colombo, 2009.

CHAIGAR, V. A. M.; MADRUGA, E. B.. Imaginários, cheiros, formas e cores de lugares de crianças e repercussões em adultos discentes de Pedagogia. Instrumento: R. Est. Pesq. Educ., Juiz de Fora, v.17, n.2, 2015.

CORDEIRO, J. C. S.. Relato de Experiência do Projeto de Trabalho Educação Ambiental com a reciclagem de sucatas na construção de jogos e brinquedos. Monografia (Especialização em metodologia da educação física) Universidade do Estado do Amazonas, Manaus, 2015.

CRUZ, G. L.. Dicionário das Plantas Úteis do Brasil. 5 ed. Rio de Janeiro: Bertrand do Brasil, 1995.

DIÓGENES, M. J. N.; MATOS, F. J. A.. Dermatites causadas por plantas. Anais Brasileiro de Dermatologia. v.74, n.6, p.629-634, 1999.

FORTES, J. C.; GUEDES, M. I. F.. Atividade antimicrobiana do óleo essencial de Croton Argyrophylloides Muell Arg e de frações isoladas dos extratos de Astronium urundeuva (Allemão) Engl. In: REUNIÃO ANUAL DA SBPC, 58. Anais. 2006.

FREITAS, A. K. M.. Psicodinâmica das cores em comunicação. 6 ed. Limeira, 2007.
ISCHKANIAN, S. H. D.; MACIEL, E. R. S.. O lúdico: brinquedos, brinquedos e brincadeiras na construção do processo de aprendizagem na educação infantil. Revista Eletrônica Mutações, 2017.

LIMA, B. G.. Caatinga: espécies lenhosas e herbáceas. Mossoró: Edufersa, 2012.

LORENZI, H.. Arvores brasileiras. 1 ed. Nova Odessa: Platarum, 2009.

MAINIERI, C.; CHIMELO, J. P.. Fichas de características das madeiras brasileiras. São Paulo: Instituto de pesquisas tecnológicas, 1989.

MARANGON, G. P.; FERREIRA, R. L. C.; SILVA, J. A. A.; SOUZA e LIRA, D. F. S.; SILVA, E. A.; LOUREIRO, G. H.. Estrutura e padrão espacial da vegetação em uma área de caatinga. Floresta, Curitiba, v.43, n.1, p.83-92, 2013.

MEDEIROS NETO, P. N.; OLIVEIRA, E.; CALEGARI, L.; ALMEIDA, A. M. C.; PIMENTA, A. S.; CARNEIRO, A. C. O.. Características físico-químicas e energéticas de duas espécies de ocorrência no semiárido brasileiro. Ciência Florestal, Santa Maria, v.22, n.3, p.579-588, 2012.

MELO, J. E.; CAMARGO, J. A. A.. A madeira e seus usos. SFB/LPF/MMA. 2 ed. Brasília, 2016.

MONTEIRO, J. M.; ALBUQUERQUE, U. P.; NETO, E. M. F. L.; ARAÚJO, E. L.; ALBUQUERQUE, M. M.; AMORIM, E. L. C.. The effects of seasonal climate changes in the Caatinga on tannin levels in Myracrodruon urundeuva (Engl.) Fr. All. and Anadenanthera colubrina (Vell.) Brenan. Brazilian Journal of Pharmacognosy, v.16, n.3, p.338-344, 2006.

MORESCHI, J. C.. Propriedades tecnológicas da madeira. Curitiba, 2005. 
MOTA, C. W. C.. Efeito da chalconas (Myracroduon urundeuva Fr. All.) nas fraturas expostas induzidas em ratos. Dissertação (Mestrado em Curso de Pós Graduação em Cirurgia) - Universidade Federal do Ceará, 2006.

NETO, P. N. M.; OLIVEIRA, E.; PAES, J. B.. Relações entre as Características da Madeira e do Carvão Vegetal de duas Espécies da Caatinga. Floresta Ambiente, v.21, n.4, p.484493, 2014

OLIVEIRA, C. S.; MAIA, E. B. S.; BORBA, R. I. H.; RIBEIRO, C. A. Brinquedo Terapêutico na assistência à criança: percepção de enfermeiros das unidades pediátricas de um hospital universitário. Rev. Soc. Bras. Enferm. Ped. v.15, n.1, p.2130, 2015.

OLIVEIRA, F.. Fundamentos de Farmacobotânica. São Paulo: Atheneu, 1989.

PAES, J. B.; LIMA, C. R.; OLIVEIRA, E.; MEDEIROS NETO, P. N.. Características físico-química, energética e dimensões das fibras de três espécies florestais do semiárido brasileiro. Floresta e Ambiência, v.20, n.4, p.550-555, 2013.

PELL, S. K.. Molecular systematics of the cashew family (anacardiaceae). Thesis (Doctor of Philosophy Biological Sciences) - Faculty of the Louisiana State University, 2004.

PIMENTA, S. B. B.. Estudo sobre mediação e desenvolvimento humano na teoria de Vigotski: reflexões sobre a criança em situação de adoecimento. Dissertação (Mestrado em Psicologia) - Universidade Federal de Goiás, Goiânia, 2017.

RAMOS, J.; FERRIOLI, A. C.. Projeto de brinquedo que estimule a organização para crianças de quatro a seis anos produzido com material natural. In: CONGRESSO DE PESQUISA E EXTENSÃO DA FSG, 1. Anais. Caxias do Sul, 2013.

RIZZINI, C. T.. Arvores e madeiras úteis do brasil: Manual de dendrologia brasileira. 9 ed, São Paulo: Bucher, 2008.

SANTANA, J. A. S.; JÚNIOR, J. A. S. S.; BARRETO, W. S.; FERREIRA, A. T. S.. Estrutura e distribuição espacial da vegetação da Caatinga na Estação Ecológica do Seridó, RN. Pesq. flor. bras., Colombo, v.36, n.88, p.355-361, 2016.

SANTOS, R. C.; CARNEIRO, A. C. O.; PIMENTA, A. S.; CASTRO, R. V. O.; MARINHO, I. V.; TRUGILHO, P. F.; ALVES, I. C. N.; CASTRO, A. F. N.. Potencial energético da madeira de espécies oriundas de plano de manejo florestal no Estado do Rio Grande do Norte. Ciência Florestal, 2013.

SANTOS, W. S.; SOUZA, M. P.; NÓBREGA, G. F. Q.; MEDEIROS, F. S.; ALVES, A. R.; HOLANDA, A. C.

Caracterização florístico-fitossociológica do componente lenhoso em fragmento de caatinga no município de Upanema-RN. Pesquisas Agrárias e Ambientais, Nativa, Sinop, v.5, n.2, p.85-91, 2017

SILVA, R. C. S.; FERREIRA, R. L. C.; SILVA, J. A. A.; MEUNIER, I. M. J.; BERGER. R.. Aspectos fitossociológicos e de crescimento de Commiphora leptophloeos no semiárido brasileiro. Pesquisa Florestal Brasileira. v.37, n.89, 2017.

SJÖSTRÖM, E.. Wood chemistry: fundamentals and applications. 2 ed. New York: Academic Press. 1993.

ZATZ, S.; ZATZ, A.; HALABAN, S.. Brinca Comigo!: Tudo sobre o brincar e os brinquedos. São Paulo: Marco Zero, 2007.

A CBPC - Companhia Brasileira de Produção Científica (CNPJ: 11.221.422/0001-03) detém os direitos materiais desta publicação. Os direitos referem-se à publicação do trabalho em qualquer parte do mundo, incluindo os direitos às renovações, expansões e disseminações da contribuição, bem como outros direitos subsidiários. Todos os trabalhos publicados eletronicamente poderão posteriormente ser publicados em coletâneas impressas sob coordenação da Sustenere Publishing, da Companhia Brasileira de Produção Científica e seus parceiros autorizados. Os (as) autores (as) preservam os direitos autorais, mas não têm permissão para a publicação da contribuição em outro meio, impresso ou digital, em português ou em tradução. 